\title{
16
}

\section{Hybridity in Port Moresby: Gender, Class and a 'Tiny Bit of Feminism' in Postcolonial Papua New Guinea}

Ceridwen Spark

\section{Introduction}

In 2007, I was staying at the Holiday Inn in Port Moresby, Papua New Guinea (PNG), with my family. During this time my friend Karuka (a pseudonym) came to visit us. Knowing that my children would appreciate company to combat the boredom of being trapped in a Port Moresby hotel, she brought with her three of her younger siblings. On arrival at the front gate, Karuka and her family were forbidden entry by one of the security guards on duty. It was only when I went to the gate and clarified that the group were there to see us that they were allowed in.

Initially this incident appeared to be a case of 'misreading' Karuka on the part of the security guard. As those who spend time in Port Moresby's hotels can attest, the guards are employed to 'keep out' undesirables as much as to ensure the physical safety of the paying guests. In the colonial era, this was simple-only expatriates or (sometimes) Papua New Guineans who entered with expatriates were allowed in to the more salubrious locations that in practice served as unofficial enclaves allowing expatriates to live 
separately from those around them. ${ }^{1}$ Since independence and the gradual emergence of a middle class in PNG, deciding who may or may not enter a place has become more complicated. My perceptions and anecdotal evidence suggest guards make their boundary-keeping decisions on various aspects of a person's appearance, including skin colour, ethnicity and clothing.

Usually, someone like Karuka-overseas educated and well dressedwould drive in to the premises, thus avoiding scrutiny and being allowed to 'pass' by virtue of having arrived in a car. Cars themselves mark 'class' because of their prohibitive cost in PNG. But, in this instance, having walked up to the gate with other locals, Karuka was vulnerable to the guard's subjective interpretation of her 'status' and his assessment of whether she and her family were allowed to enter the space. Unfortunately, the boundary keeping did not end there. Later that day, the same guard asked Karuka and her family to leave the poolside area because it was only for 'paying guests'. Given that middle class Papua New Guinean families who are not staying at the hotel regularly use the pool on weekends, it is perhaps unsurprising to learn that the guard had something of a vendetta against Karuka and her family.

Karuka recognised the guard as being from Hohola, where she grew up and where her family still lives. Like much of urban PNG, Hohola is characterised by mixed housing including squatter settlements, underlying and sometimes violent ethnic tension, and inadequate and unreliable access to utilities. That the guard from Karuka's area used his role as a (literal) gatekeeper to exercise the form of authority to which he had access needs to be understood through reference to Karuka's perceived privilege. Having won scholarships to attend school and then university overseas, Karuka has lived away from home since the age of 16, making occasional visits to see her family. At the time we coincided in Port Moresby, she was in town staying with her family while on holiday. Karuka said that the guard knew who she and her siblings were and speculated that he refused them entry in an attempt to reassert power over her because he viewed her as a bikhet meri ('show-off woman'). As I have noted elsewhere, in urban PNG men have little to gain from supporting greater equality between men and women, at least in the short term. ${ }^{2}$ But they can defend their own interests and negate the potential power

1 Alpers, 'Medical Research in the Highlands'; Gammage, 'Moresby 1966'.

2 See Spark, 'Gender Trouble in Town'. 
of educated and employed women by appealing to idealised versions of gender roles which locate women's 'proper place' as being in the home. As an extension of this they can also refuse women entry to the places that are associated with the benefits of modernity. In my view, this was the dynamic evident between the guard and Karuka.

In their seminal work, Emerging Class in Papua New Guinea, anthropologists Gewertz and Errington discuss what they call the 'hidden injuries of class' as these play out between 'grass roots' and middle class Papua New Guineans living in Wewak. ${ }^{3}$ Writing in the late 1990s, they note an increasing tendency among middle class Papua New Guineans to construct people from the 'grass roots' as the 'blameworthy poor'. ${ }^{4}$ Demonstrating 'what happens to the poor when class has become a fait accompli, they construe middle class Papua New Guineans as detaching from less-affluent kin and acquaintances in order to protect their resources. ${ }^{5}$ But as Karuka's experience with the guard indicates, people on both sides of the class border harbour stereotypes and prejudices against one another. Importantly, these interactions involve gender, not in an additive sense but at their core. While Karuka may have 'made it out' of the Moresby settlement by virtue of her education, on returning to visit her family in Port Moresby she temporarily inhabits the same world as the security guard, and in this world she is still regarded as a daughter and sister of people known in a particular locality. And here, as in most places now construed as postcolonial, encounters between 'others' reveal a complex interplay between ethnicity, gender and class that inform and underpin ideas about who is entitled to go where. Karuka's difficulty entering and spending time in the spaces of the hotel demonstrates that in contemporary Port Moresby inclusion and exclusion, while class based, also reflect and affect the ways in which gender and ethnicity are constructed and understood.

Such encounters are common in PNG, and other middle-class and tertiary-educated women have told me about similar experiences. In these scenarios, male security guards, who typically have received only primary education, are endowed with a dubious power and responsibility. ${ }^{6}$ Policing the boundaries of the city's locations on the basis of their subjective

\footnotetext{
3 Gewertz and Errington, Emerging Class in Papua New Guinea.

4 Ibid., 84.

5 Ibid., 84.

6 See Lusby, 'Preventing Violence at Home'; Sharp et al., 'The Formal, the Informal and the Precarious'. See also Lusby, 'Securitisation, Development and the Invisibility of Gender'.
} 
assessment of the class credentials of those seeking to enter, they are well positioned to turn these moments into opportunities to reassert what they perceive to be their 'rightful' place in the gender hierarchy, embarrassing middle class women in the process. As Sharp et al. note, 'employment as a security guard presents one of few options for men with little or no formal education, but wages are barely enough to sustain their families'. ${ }^{7}$ The point here is not to 'blame the guards' but rather to note that the rank and file guards who occupy the lowest rungs of PNG's lucrative security industry both reflect and are expected to enact 'a hierarchy of social class and economic privilege in $\mathrm{PNG},{ }^{8}$ As everyday instances of boundary making, such interactions and the hybridity they embody can be analysed to ground discussions of the power dynamics of 'race, gender and class as these are enacted at both the local and global levels. .' Below, I describe my approach to reading hybridity in Port Moresby, an approach which is descriptive rather than prescriptive and in which Karuka remains a central character.

There are many ways to explore hybridity in Port Moresby, not least because it is a rapidly expanding city, both in terms of its physical infrastructure, but also with regard to the population, now estimated to be as high as three quarters of a million. ${ }^{10}$ But following Laura McLeod's injunction to notice the 'diversity of the personal' and to 'pay deeper attention to the diverse ways in which the personal is political for both international and local actors', ${ }^{11}$ I have chosen to consider hybridity as it is represented in the personal views that two 'international' women have about one of the city's new locations, namely Cafe Duffy located in the suburb Gordons.

As one of the new places that is part of the 'dynamic, exciting, dangerous, bewildering, hybrid environment that is Moresby', it would be easy to argue that Duffy merely represents the global spread of cosmopolitan consumerism. ${ }^{12}$ But closer inspection reveals the cafe to be a hybrid site. As I argue here, Duffy is characterised by a blending of cultures which underpins and enables the development of perhaps more subversive modes of being than would usually be associated with places made for

\footnotetext{
7 Sharp et al., 'The Formal, the Informal and the Precarious', 3.

8 Ibid.

9 Darling-Wolf, 'Disturbingly Hybrid or Distressingly Patriarchal?', 70.

10 Jones and Kep, 'Understanding Urbanisation in the PNG Context'.

11 McLeod, 'A Feminist Approach to Hybridity', 52.

12 Goddard, 'Introduction: About Moresby', 18; see also Foster, Materializing the Nation; Foster, Coca-Globalization.
} 
consumption. My analysis of Duffy demonstrates that the site plays a role in the production of new sociospatial practices and identities - with the potential to challenge the dominant constructions of class and gender in Port Moresby.

To make my argument, I draw on a range of sources, including photos and commentary that Karuka shared with me after her November 2015 visit to Port Moresby; my interviews with young middle class women who live in Moresby, including an interview I conducted with Duffy's French owner and manager, Olga Girault; and a postcard that Girault designed to advertise Duffy. Typically, even within conceptualisations of hybridity, the 'international' is represented as being 'a structure or organisation' with the local construed as 'personal'. I challenge this construction, demonstrating that the 'international' can also be 'personal' and deeply imbricated with the 'local'. ${ }^{13}$ Invoking the term hybridity in a manner consistent with discussions that occur in postcolonial explorations of identity, place and culture, ${ }^{14}$ and which reflect a process in which hybridity has the potential to 'dislocate the process of colonization', ${ }^{15}$ I argue that the emergence in Port Moresby of places such as Duffy indicates something other than the 'failures of postcolonial development ${ }^{16}$ or the dominance of consumption-based place making. Allowing young Papua New Guinean women an appealing palette of experience that is otherwise difficult to access in PNG, Duffy enables women to construct themselves as friends and customers - rather than daughters, wives or sisters-and in doing so provides momentary liberation from the ordinary constraints of life in Port Moresby.

\section{Cafe Duffy: Karuka's perspective}

Karuka grew up in Hohola, a suburb of Port Moresby then considered a dangerous place. ${ }^{17}$ The first of three daughters in a family left by their father she had a profound sense as a child that she and her family were 'at the bottom of the pile', saying 'we were almost like subordinates' and

13 McLeod, 'A Feminist Approach to Hybridity'.

14 See Bhabha, 'Questions of Cultural Identity'; Cuninghame, 'Hybridity, Transnationalism, and Identity'; Darling-Wolf, 'Disturbingly Hybrid or Distressingly Patriarchal?'; Jacobs, Edge of Empire.

15 Cuninghame, 'Hybridity, Transnationalism, and Identity', 21.

16 Connell, 'Regulation of Space in the Contemporary Postcolonial Pacific City', 245.

17 See Spark, 'Gender Trouble in Town'; Spark, 'An Oceanic Revolution?' and Spark, “We Only Get the Daylight Hours'” for other discussions of Karuka’s background and experience. 
that, even at a young age, there was 'already the sense that we were lower'. Perceiving overseas education as something that only the wealthy could afford, she thought 'that happens to those wealthy people, but not to us'. Indeed, Karuka says it was only when she gained a scholarship and left PNG that she came to think that class need not determine opportunity in every case. Though currently completing postgraduate study in New Zealand, Karuka's background and experience growing up in Moresby continue to shape her analysis of class interactions in the city.

Aged 33, Karuka had not been back to Moresby for three years when she went in late 2015. Interested in her impressions of the rapidly changing city, I asked her to send me photos and thoughts about the places she visited. She did this using WhatsApp and later produced a PowerPoint presentation, with accompanying commentary. I have extracted from this in the following discussion. One place Karuka took photos was Cafe Duffy where she went with two friends.

Duffy was established in 2012 by 22-year-old Olga Girault and her partner, local businessman Travers Chue, whose PNG-Chinese father owns Pacific Industries, a company that produces a range of drinks and foodstuffs sold across PNG. In contrast to the 'new Chinese investors in Papua New Guinea' who, as Graeme Smith notes, 'fit Erving Goffman's definition of a group that is "disqualified from full social acceptance", on the basis that they tend to be perceived as mercenary and racist, ${ }^{18}$ Pacific Industries has existed in PNG for 60 years and both the company and Duffy have an image of having successfully 'localised'. ${ }^{19}$ Part of the group of what Smith calls 'old Chinese', they tend to be seen and to see themselves as 'more benevolent' and 'less aggressive' than the 'new Chinese' operating in PNG since 2007.

On one hand, the cafe represents a positive image of national and urban development of the kind dear to 'elites and governments'.$^{20}$ Indeed, Duffy has had such a positive reception that PNG's National Airport Corporation invited Girault to establish a second cafe at the international airport when the airport was renovated for the 2015 Pacific Games. In 2016, Girault and Chue opened a third cafe at Harbour City located in Port Moresby's banking and financial hub and, because of gated security,

18 Smith, 'Beijing's Orphans?', 327.

19 Ibid.

20 Connell, 'Regulation of Space', 248. 
an area difficult to enter without a car. But despite the cafe's obvious association with the city's professional elites, it would be erroneous to see Duffy merely as an embodiment of wealth, privilege and consumerism in the midst of a 'planet of slums'. ${ }^{21}$ As feminist geographer Gillian Rose points out, spaces are 'extraordinarily complicated', allowing for a range of interpretations and meanings. ${ }^{22}$ While recognising Harvey's insight that the contemporary urban experience gives (only) those with money the aura of freedom of choice, ${ }^{23} \mathrm{I}$ intend to explore the prospect that Duffy affords a greater range of rights and freedoms than might initially be thought.

Having become interested in Duffy as a site that reflects aspects of the 'new Port Moresby', I interviewed Girault in August 2015. She said the cafe's clientele are 'now around 50/50' in terms of ethnicity (that is, half expatriate and half Papua New Guinean). On the three occasions I have visited (the original) Duffy, the clientele has included professional Papua New Guineans as well as expatriates. But Girault said she noticed that some Papua New Guineans 'will only purchase take away', perhaps suggesting they are not entirely comfortable to spend time in the space of the cafe. Cindy, a 33-year-old Papua New Guinean friend of Karuka's said that when she and her boyfriend went for brunch they were the only Papua New Guineans there 'apart from the ladies behind the counter'. Consequently he was uncomfortable and wanted to 'sit in the corner'. Though Cindy explicitly constructs her boyfriend's discomfort in terms of ethnicity, it is also possible that Papua New Guinean men see Duffy as a feminine space, and that this rather than racism underpins their discomfort.

Duffy sells coffee, pastries, smoothies, juices and fresh bread, alongside a range of lunch items. With the exception of the fresh fruit and vegetables, most of which are locally sourced, the produce comes from Australia and New Zealand.

Along with the range, the quality of the food and beverages is rare in PNG, offering, as Girault says 'the best we can' and 'the best coffee in town'. The commentary accompanying Karuka's photos testifies to this:

21 Harvey, 'The Right to the City', 37.

22 Rose, Feminism and Geography, 155.

23 Harvey, 'The Right to the City', 31. 
Duffy's cafe—-at] 5 mile, had ace food—chocolate croissant —amazeballs. Location is ok as well, although it's in the Gordons industrial area so I had initially been a little hesitant to go. But security was awesome. Duffy however can only be accessed by well to do people. Eg. My sisters mentioned 'only money people go there' and that they hadn't been.

In addition to reporting that her sisters saw Duffy as a place for 'money people', Karuka also told me (in person) that she would not take them there because it would be like 'opening a world to them that they could never have again', once she was not in the country to pay for the experience. Representing a more optimistic perspective, Girault told me 'this coffee shop is open to everyone .... and everyone is welcome to come here'. Realistically, however, the cost of the produce (a sandwich and drink costs around 40 PNG kina, which is equivalent to approximately AU \$20) means that Duffy can only be afforded by a small proportion of Port Moresby's population.

In advanced capitalist societies, where individualism goes hand in hand with modernity, access by virtue of one's capacity to pay is widely accepted as part of life. But in PNG, places such as Duffy give rise to painful tensions for people like Karuka. On one hand, Duffy represents some of the positives of global capitalism and globalisation, including an opportunity for young women to participate in cosmopolitan consumerism, which, in PNG as elsewhere, tends to be associated with forms of (gendered) freedom and autonomy. For Karuka and her friends who can afford to visit Duffy, the site offers a valued opportunity to take part in the global cosmopolitan culture represented by purchasing quality cakes and coffee in their 'home' town. As Maggie Cummings writes, it is helpful to understand the social change associated with globalisation not as 'something that happens to the people whose lives we study, but rather, something that they themselves do, participate in, drive, and shape through their own choices, actions, feelings, and theories'. ${ }^{24}$ Viewed through this focus on agency, we can see that when educated and professional women enter the space of Duffy they are participating in the "better future'25 that globalisation can and does deliver to Port Moresby inhabitants who do have money.

24 Cummings, 'Imagining Transnational Futures in Vanuatu', 383.

25 Ibid., 381. 
On the other hand, Duffy provides a stark reminder that 'quality' can only be afforded by a few, thus representing the problems associated with urbanisation and reliance on a cash economy. ${ }^{26}$ Of course affordability also determines access in advanced capitalist societies, but in PNG, 'hybrid' women like Karuka are related to and otherwise intimately connected with the many who feel uncomfortable about or cannot afford to go inside. As Keith Barber notes in his study of urban households, 'it is not as individuals that people survive in PNG' ${ }^{27}$ Having grown up in a context in which reciprocity and resource sharing continue to form the basis of life and survival for many, including in many instances, themselves, Karuka and other overseas-educated women with whom I have spoken maintain a degree of commitment to this mode of life. Almost all the young women I know help to support their family members, including by paying for housing, food or assisting to educate younger siblings, nephews and nieces. At the same time, like other members of PNG's middle class, they also seek to establish a degree of autonomy from family and tend to reject the financial demands made on them by members of their extended families, preferring to limit their sharing to immediate family members. ${ }^{28}$

While the middle class in PNG are maligned for turning their backs on their grass roots counterparts, internationally educated and cosmopolitan women such as Karuka are acutely aware that they are products of a context in which some are afforded more opportunities than others. Moreover, this perspective is shaped in equal measure by local connections (including, for example, Karuka's relationship with her sisters, whom she financially supports) and experiences such as the one Karuka had with the guard in 2007, as by her international education and outlook. Thus, in this interaction between an apparently 'international' person and a 'local' place, Duffy is a paradoxical space in which both people and place are shown to be hybrid.

\footnotetext{
26 Ibid., 383.

27 Barber, 'Urban Households, Means of Livelihood and Village Identity in Moresby', 95.

28 Cox and Macintyre, 'Christian Marriage, Money Scams, and Melanesian Social Imaginaries'; Gewertz and Errington, Emerging Class in Papua New Guinea; Macintyre, 'Money Changes Everything'.
} 


\section{Cafe Duffy: Olga's perspective}

To add to the complexities of 'reading' Duffy's hybridity within a modern PNG, it is worth delving further into Girault's perspective as Duffy's manager, for while she initially appears to represent the 'consumption economy', ${ }^{29}$ she too complicates easy dichotomies. Two things in particular stand out. The first is Girault's approach to her staff, which, being respectful and mutually supportive, seems positively postcolonial in comparison to the more colonial master-servant relationships between employers and guards evident at most salubrious locations in PNG. Indeed, as Lusby notes, employer-guard relationships are characterised by violence, including 'disciplinary beatings for breaches of the rules'. ${ }^{30}$ A closer look at Girault's perspective clarifies that she has transformed the role played by security at Duffy, encouraging them to see would-be entrants as customers rather than as constituting a threat.

Like most places in Moresby that expatriates frequent, there are security guards at the gate outside the entrance to Duffy. But these guards look noticeably different from others in PNG (Figure 16.1). Notably, they are not wearing a police or military style uniform or carrying batons as is commonly the case with guards working for private security companies. On arriving at Duffy, one observes that they appear happy and at ease and have warm and welcoming relationships with customers, rather than the typically deferential ones evident in other expensive locations. Wearing cheerful, rather than mirror sunglasses, they look more like they are on holiday than they do intimidating. As Karuka noted above, 'security was awesome' and Grace, a friend of Karuka's, said she noticed the 'very cheerful and enthusiastic attitude' of the guards. These comments appear to reflect the pleasure that the guards' welcoming attitude gives customers, many of whom, like Karuka, have experienced guards intimidating them and policing their appearance and 'right to the city'.

29 Clifford, 'On Collecting Art and Culture', 141.

30 Sharp et al., 'The Formal, the Informal and the Precarious', 3. 
16. HYBRIDITY IN PORT MORESBY

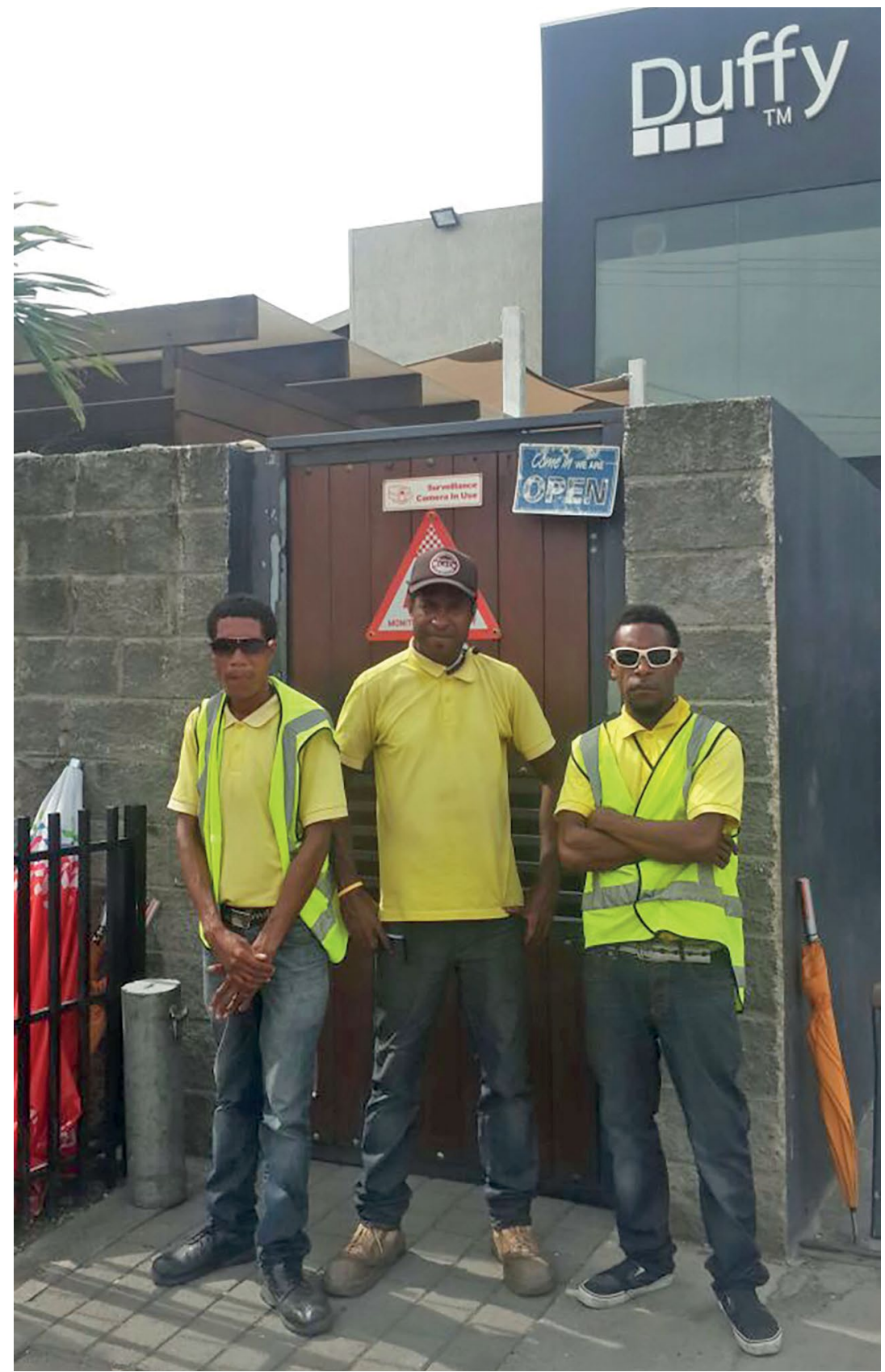

Figure 16.1: The friendly security team at Duffy

Source: Karuka (pseudonym), published with permission. 
Discussing Duffy's security staff, Girault told me the story of their employment, describing how the guards had become part of the 'Duffy family':

We had a small number of staff and one of our first security [guards] was a guy who was in the streets actually and he was really malnourished, very skinny, had no family, he looked so sad ... And now we're his family pretty much. So it's like all the people that are working with us all have a story with us but we are also a family, we call it the Duffy family so we say you have your family in the village but this is your second family, this is your Duffy family. So they're all very loyal, all our security guards, they have been with us since day one.

Incorporating members of PNG's 'underclass' into 'the Duffy family', Girault reverses the usual anthropological pattern in which the visiting international 'other' is fitted in to local kinship systems. This incorporation represents an implicit critique of those in the middle class who attempt to 'detach' from their less-affluent kin, thus challenging the neoliberal view that people are 'poor because they make bad decisions' - a view Karuka also critiques since leaving PNG. Girault's 'everyday political analysis ${ }^{31}$ of the situation in which the once homeless and hungry guards found themselves before being employed at Duffy is indicative of her border-crossing (as opposed to border-reinforcing) hybrid identity and politics. ${ }^{32}$ The 'Duffy family' suggests the need to read the new places of Port Moresby as reflecting and allowing a new mixing between cultures and people, which challenges existing borders of the political and ethnic communities in this context.

As noted above, this mixing between people and cultures is evident in the security guards' interactions with customers. Guards display an obvious familiarity with customers, expatriate and otherwise, and there is a warmth and egalitarianism about their interactions at the entrance to the cafe. Girault says that she and Chue actively encouraged this way of relating, providing 'incentives' for the guards to 'remember the customers' names' and greet them warmly.

Now we don't need to tell them anything. They love it, they love having relationships with customers and get treated so well by customers. Every Christmas, they get so many gifts because customers love them.

31 Hudson et al., Everyday Political Analysis, 1.

32 Cuninghame, 'Hybridity, Transnationalism, and Identity', 29. 
Matthew, one of Duffy's security guards, confirmed the gift-giving relationship with customers, saying:

We know our regular customers by name and they know us by our names and that makes us feel good. Sometimes when we become familiar, become friends, with a particular customer, and when he or she leaves to go back to where they come from, we [the guards] give them bilums and other PNG gifts. In return they give us gifts like clothes and other things.

Indeed, as Girault told me, some guards became so familiar they were kissing customers when they arrived-perhaps an over emulation of the French Girault - and she had to explain that this was going 'too far'. As Iyall Smith notes: 'those who occupy hybrid spaces benefit from having an understanding of both local knowledge and global cosmopolitanism. Those who can easily cross barriers in a world of amorphous borders have an advantage. ${ }^{33}$ The guards' kissing, which perhaps constitutes a moment of 'excessive' border crossing, serves as a reminder that familiarity with the 'global' language of customer service within a 'local' context is a valuable skill in a hybrid environment.

Girault's hybrid perspective is also captured in a postcard she produced to advertise the cafe. Using Roger Violett's famous image of two French women entitled 'Café et cigarette, Paris, 1925', Girault asked her sister to digitally adapt the image by painting the two French women in bilas, traditional PNG decoration usually worn at celebrations and big events. As Girault explained, the image of women enjoying coffee and the reflection of this as bilas and painting on their bodies captures her own experience of drinking Papua New Guinean coffee, a moment, she says, that always makes her 'feel a little bit Papua New Guinean'. ${ }^{34}$ Demonstrating the ways in which local and global cultures blend to create something new, the altered image of women enjoying leisure and friendship has a political potency in PNG where women continue to be constructed primarily through reference to their domestic and child-bearing responsibilities.

The desire to refigure local versions of femininity was another of Girault's motivations for adapting and utilising this French image to advertise Duffy.

33 Iyall Smith, 'Hybrid Identities', 4.

34 See West, From Modern Production to Imagined Primitive, for a comprehensive analysis of the social world of coffee in PNG. 
I really like the picture of these two ladies, and ... I'm really trying to empower women here. I guess I'm a tiny bit feminist, a little hint that I'm always for the women. I have meetings with the girls where I'm always you have to be proud independent blah blah blah, because especially in this country. Anyway for me it's symbolic to have those two women having a coffee. Women you know.

Noting 'it is socio-spatial practices that define places and these practices result in overlapping and intersecting places with multiple and changing boundaries', ${ }^{35}$ feminist geographer Linda McDowell reminds us that what women do where changes the 'nature' of a place. While to a large extent normalised among women in the middle classes of advanced capitalist societies, meeting friends for coffee is still not the norm for most women in PNG. Consequently, when Papua New Guinean women come together in a place like Duffy to do just that, they are perhaps embodying a 'tiny bit of feminism' while simultaneously changing the local place in which they are engaged in this spatial practice. Playfully capturing a more optimistic perspective on the global flows that characterise transnationalism, the revamped postcard encapsulates a different perspective on young women's leisure and consumption practices, demonstrating that while Parisian women can become 'a little bit' Papua New Guinean, so too can Papua New Guinean women become 'a little bit' French. ${ }^{36}$

\section{Conclusion}

Taking a descriptive over a prescriptive approach and rather than trying to 'create or administer hybridity', ${ }^{37}$ I have sought to demonstrate the value of hybridity for understanding the rapidly developing city of Port Moresby. I have observed how Karuka's and Olga's 'international' perspectives on Duffy, a particular place in their 'home town', enable us to consider hybridity in relation to the power dynamics of race, gender and class in contemporary Port Moresby. As this detailed analysis of their perspectives makes clear, 'exposure to global communication and culture plant the seeds for the formation of a hybrid culture'. ${ }^{38}$ Discussing moments and places where this hybridity is embodied, I have shown it is

35 McDowell, Gender, Identity and Place, 4.

36 Compare with West, From Modern Production to Imagined Primitive.

37 Miller, 'Disaggregating Hybridity', 3.

38 Iyall Smith, 'Hybrid Identities', 5. 
insufficient to argue that class operates in PNG to produce boundaries on which the 'oppressed' and the 'empowered' exist on opposite sides. ${ }^{39}$ Rather, it is useful to take a perspective on everyday boundary making which elucidates 'the mixed and melded cultural forms that [are] ever more common in a globalized world'. ${ }^{40}$ The analysis also reveals that 'hybrid' women such as those discussed in this chapter may be best placed to challenge the suspicions and 'othering' narratives that people on both sides of borders 'tend to harbour against each other' ${ }^{41}$ and which were manifest in Karuka and the guard's interactions at the Holiday Inn in 2007. Demonstrating that gender intersects with class and ethnicity to produce new versions of people and place that defy neat categorisation, I have shown that Port Moresby both is, and continues to become, a more interesting, complex and hybrid place than it is usually represented to be.

39 For a discussion of boundary making, see Kyed, 'Introduction to the Special Issue: Legal Pluralism'.

40 Miller, 'Disaggregating Hybridity', 3.

41 See Cuninghame, 'Hybridity, Transnationalism, and Identity'. 
This text is taken from Hybridity on the Ground in Peacebuilding and Development: Critical Conversations, edited by Joanne Wallis, Lia Kent, Miranda Forsyth, Sinclair Dinnen and Srinjoy Bose, published 2018 by ANU Press, The Australian National University, Canberra, Australia.

doi.org/10.22459/HGPD.03.2018.16 